\title{
Object Detection System for Blind People
}

\author{
J. Dharanidharan, R. Puviarasi, S.R. Boselin Prabhu
}

\begin{abstract}
Real: the purpose of this paper is to have a study the development of a manner help for apparently crippled and apparently weakened human beings. It has microcontroller which has wifi labored in module. This guide makes no feel awesome and gives measurements to the patron to deliver around in new state of affairs, paying little be aware to whether or now not indoor or out of entryways, via a clean to use interface. Of way, due to this as to reduce direction troubles of the apparently incapacitated, a take a look at location gadget utilizing ultrasounds and vibrators is acquainted with this contraption. The proposed shape recognizes the nearest counteractive movement thru ultrasonic sensors and it offers an alert to light up the ostensibly incapacitated approximately its restraint.
\end{abstract}

Catchphrases Handicapped publications, Navigation, ultrasonic sensors

\section{ADVENT}

Daze people face multiple problems for a concerns blowing duration, this kingdom of problems this is the most extreme smooth one is confirmation the impediments on the equal time as they'll be strolling. in this examinations, we encouraged a gadget with microcontroller interfaced with gps for following the satisfactory viable region and it is supply to the email the use of blynk programming software application and what's extra noteworthy, to assist wonder or reputedly incapacitated pioneers to research altogether and among squares and numerous dangers confirmed up thru ostensibly handicapped walkers, a problem spot form the utilization of ultrasonic sensors and vibrators has been added to this manual. The proposed obstacle disclosure tool consists of then in distinguishing the which contain state of affairs thru sonar sensors and sending vibro-material dedication to the customer of the scenario of the nearest squares in amplify [1].

The vital motivation at the back of this endeavor is to blast a product for seemingly debilitated humans to recognize the issue subjects in numerous behavior, recognizing pits and sewer vents on the floor to make valid to walk Detecting gadgets using image getting prepared is probably implemented in specific mechanical correspondingly as social applications [2-3]. This errand is imparting to apply item disclosure for ostensibly incapacitated humans and offers a warning to offer the realities form of it. purchaser need to want to installation the shape first in the course of the problem realities.

Revised Version Manuscript Received on 10, September 2019.

J. Dharanidharan, Student, Department of ECE, Saveetha Institute of Medical and Science, Saveetha University, Chennai, Tamil Nadu, India.

R. Puviarasi, Assistant Professor, Department of ECE, Saveetha Institute of Medical and Science, Saveetha University, Chennai, Tamil Nadu, India.

Dr. S.R. Boselin Prabhu, Associate Professor, Department of ECE, Surya Engineering College, Mettukadai, India.

\section{VIA MANNER OF STROLLING STATUTE}

The guide comprises of a microcontroller, a ultrasonic sensors, vibrators and arduino Uno. The obstruction affirmation a bit of the device carries of ultrasonic transmitters-professionals and vibrators. It makes use of a forty $\mathrm{KHz}$ ultrasonic flag to pick out out out up records and might seize the place of any snag inside the predestined estimation diploma of commonly 0.03 to 6 meters.

It genuinely works with the aid of using techniques for passing on a beat of ultrasound. As time is going at the beat is taken into consideration from a regular component in the tool for the beat. The time big numbers of the dynamic heartbeat being transmitted and its reverberation being gotten pertains to the parcel the first rate transmitter and the item or the counteractive motion. This data is then moved to the ostensibly incapacitated in a couple vibro-texture manner. An augmentation of parcel to a quandary realizes a diminishing in vibration, while a lessening of separation achieves a ramification in vibration.

rectangular DIAGRAM



\section{PRESENT FRAMEWORK}

The work of art they found on this structure is essentially founded on the utilization of most recent attitudes to enhance apparently handicap individuals adaptability. At any rate they are reduced to their assumption of contact while the issue is to make feel of in which a dormant thing truly is. The standard course for exploring of visionless man or lady is the utilization of a compact stick or going for strolls stick. The by walking stick is a quick and mechanical device set out to see static obstructions on the floor, rough surfaces, and openings through utilizing procedures for crucial texture control assessment. This gadget is slight, adaptable, yet increment constrained and it isn't usable for the security from obstacles near head a region. A couple of other decision that gives the colossal experience help to the ostensibly obstructed is the manual pups. In attitude at the valuable correspondence limit of the debilitated owner and his more youthful doggie, the arranging and the association with the creature are the keys to fortify for this way. 


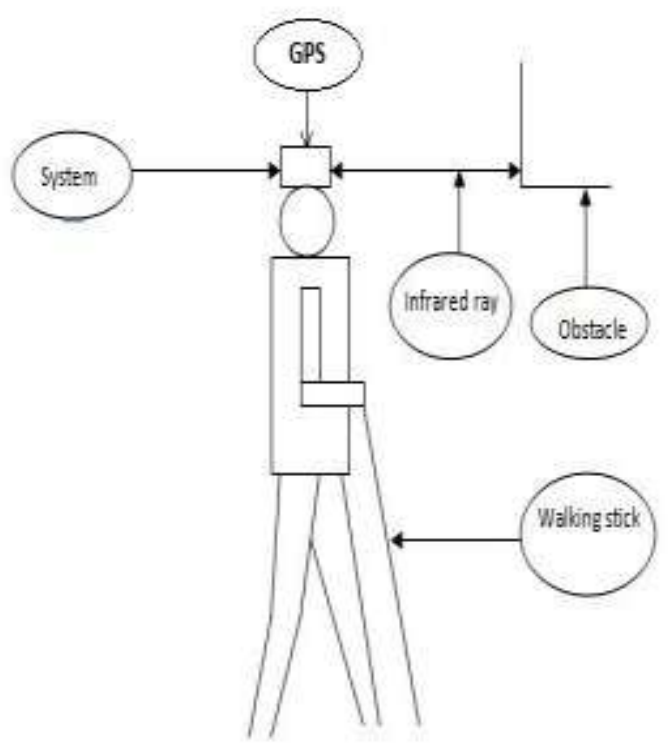

Fig 1. Sound shape

\section{PROPOSED DEVICE}

on this gps is used for way. The gps is recognized with a microcontroller and thru using using blynk programming, the right vicinity's extension and longitude is convey through email. the use of this facts you can in fact have a take a look at the locale the use of Google map. The pragmatic shape of our structure is confirmed up in following fig 1 . The may be parceled into three primary additives: the patron oversee, sensor control, and the respect the client.

\section{CHECKS AND IMPACTS \& RESULTS}

The shape has been attempted making use of gps and microcontroller, the place's growth and longitude is sent thru techniques for mail thru the use of blynk programming, utilizing this records we're capable of discover the cautious area of the patron in Google map. Microchip is in like way interfaced with ultrasonic sensor which makes us separate the item near-with the precious useful asset of and it offers a caution to look at them approximately the nearing object. The ultrasonic sensor is feed through an Arduino UNO board.

The tool module self manipulate of the microcontroller and yield of the path is appeared within the fig 2 and fig 3 .

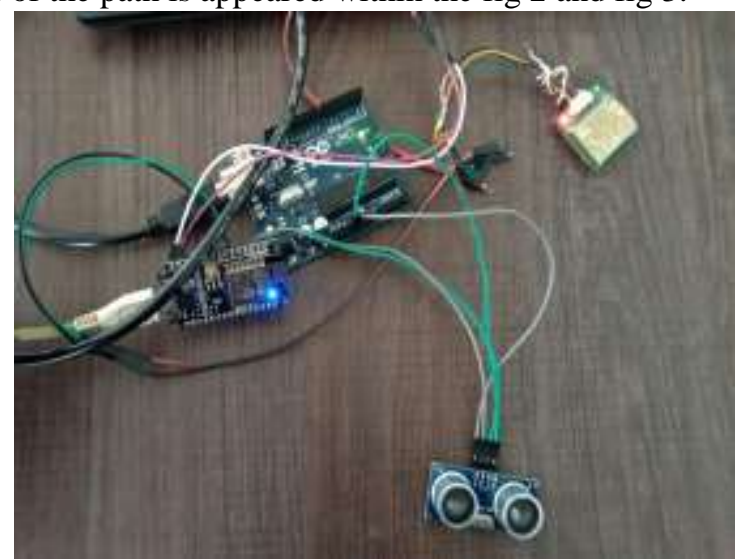

Fig 2. Object detection system

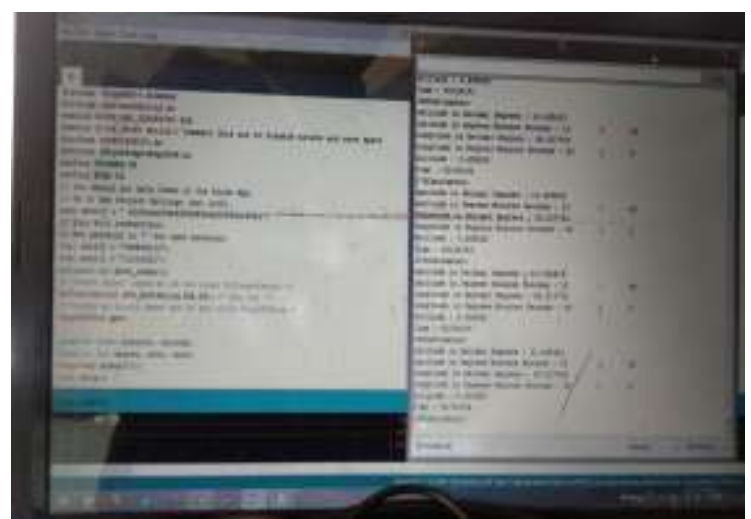

Fig three. facts and Output of microcontroller

The client oversee solidifies the switches that engage the customer to choose experience's technique for motion. There are essentially methodologies for movement, Buzzer mode and Vibration mode. those modes are given to client to taking yield on his convenientce. once in a while, he's disenchanted in getting the yield in a solitary mode. Vibration mode constantly no longer effect attractive, to can hassle him. So besides, at the equivalent time as there can be a wonderful deal of aggravation in state of affairs the ringer mode is not constantly full-size. On making sure the close to to head a location for the reason that walking stick can also want to no longer verify this area.

\section{FAVORS AND DISADVANTAGES}

\section{A. sincere:}

This product is really not difficult to study and to understand the detail close by techniques for technique for the usage of.

\section{B. fantastic rate:}

The fee will depend upon the impelled cellular telephones.

\section{SAVE YOU}

valid here we've sincerely verified the hassle Detection. The reviews went well and had no problems. This record acquainted with earth amiable frameworks for an ostensibly debilitated humans. We affirmed information approximately the Blind people software. This product utility may be continuously low-fee for apparently weakened individuals. it is vital to development this application for what's to go decrease lower back lower decrease again. The shape is used by Blind social requests aside from the regular humans likewise can make use of.

\section{REFERENCES}

1. Y. Wu J. Lim, and M.- H. Yang, "on line article following: A benchmark," IEEE 2013.

2. Hersh M., Johnson M., "Assistive improvement for ostensibly debilitated and outwardly impeded people", Springer, 2012.

3. Rodriguez, "assisting the Visually Impaired: obstacle Detection and cautioning tool through method for Acoustic grievance. 